\title{
Why Are Some Evolutionary Trees in Natural History Museums Prone to Being Misinterpreted?
}

\author{
Erica Torrens • Ana Barahona
}

Published online: 23 March 2012

(C) Springer Science+Business Media, LLC 2012

\begin{abstract}
Today, the picture of an evolutionary tree is a very well-known visual image. It is almost impossible to think of the ancestry and relationships of living beings without it. As natural history museums play a major role in the public understanding of evolution, they often present a wide variety of evolutionary trees. However, many studies have shown (Baum and Offner 2008; Baum et al. 2005; Catley and Novick 2008; Evans 2009; Gregory 2008; Matuk 2007; Meir et al. 2007b; Padian 2008) that even though evolutionary trees have the potential to engage visitors of natural history museums with the phenomena of evolution, many of them unwittingly might lead to misunderstandings about the process. As valuable research and educational institutions, one of the museum's important missions should be the careful design of their exhibits on evolution considering, for example, common preconceptions visitors often bring, such as the notion that evolution is oriented from simple toward complex organisms (incarnating the idea of a single ladder of life amidst the extraordinary diversity of organisms) and that humans are at the pinnacle of the evolutionary story, as well as naïve interpretations of phylogenies. Our aim in this article is to show from history where many of these misunderstandings come from and to determine whether five important Western natural history museums inadvertently present "problematic" evolutionary trees (which might lead to non-scientific notions).
\end{abstract}

Keywords Evolutionary trees - Evolution . Misconceptions $\cdot$ Museums $\cdot$ Images $\cdot$ Education

"Evolutionary trees," "phylogenetic tree," and "phylogeny" are used interchangeably regardless the distinctions some specialists make.

E. Torrens $(\bowtie) \cdot$ A. Barahona

Estudios Sociales de la Ciencia y la Tecnología, Universidad

Nacional Autónoma de México,

Ciudad Universitaria, Avenida Universidad 3000,

C.P. 04510, Coyoacán, México D.F., Mexico

e-mail: torrens@ciencias.unam.mx

\section{The Tree of Life: An Overview}

Evolution is the central organizing principle of biology. One of the most fundamental concepts of the theory of evolution since it was developed by Charles Darwin is that species share a common origin - commonality of descent from a single ancestor - and have subsequently diverged through time. To many, evolutionary trees are the embodiment of the theory, of the historical narrative of life. They summarize the evolution of life: Darwin's principle of the non-fixity of species, common descent, and diversification by a branching process from ancestral forms to modern ones. Thus, trees are the icons of evolution. It is almost impossible to think of the ancestry and relationships of living beings without them.

From the first decades of the twentieth century, evolutionary trees have been used in textbooks and museum displays to illustrate the process of evolution. These diagrams and images represent the emergence of species from common ancestors and their subsequent diversification or extinction. Interestingly enough, since the early twentieth century, publications for general audiences have tended to use literal representations of trees to represent human or animal evolution, as opposed to scientific publications, where the evolutionary history of organisms has normally been represented by line diagrams. Thus, in popular visual culture, ${ }^{1}$ the pictures of evolutionary trees are usually filled with images of animals and plants to show how each branch tip represents a group of organisms.

\section{Amazing Varieties}

Visual representations of evolutionary trees can be amazingly varied. Regarding their form, they can differ in shape, design, and orientation. The crucial evolutionary information of a tree is given by the branching order. As long as it remains the

\footnotetext{
${ }^{1}$ The term refers to the culturally meaningful visual content that appears in multiple forms in daily life: print images (in books, textbooks, magazines), TV, Internet, advertising, museums, etcetera.
} 
same, diagonal, curved, straight, or circular lines can be used (Gregory 2008). Trees may be oriented up or down, to the left or to the right, depending on the position of the root or point of origin. They also can be symmetrical (or balanced) if the number of species at each side of the nodes is the same, or asymmetrical (unbalanced) when not all of the groups represented contain the same number of species. For example, placental mammals are richer in species than monotremes (Crisp and Cook 2005).

Concerning the representation of organisms, evolutionary trees may represent the hypothetical relationships among the entire biodiversity or among members of a kingdom such as the animals. They can be about phyla such as the mollusks or a class such as that of the cartilaginous fishes or chondrichthyes. Orders like primates, families like composite plants, and molecules such as DNA or hemoglobin can also be represented (when using molecular data, scientists use modelling approaches like maximum likelihood and Bayesian methods (Tassy 2011)).

Regarding the method used to build them and the kind of information conveyed, evolutionary trees can be cladograms when composed by species and speciation events and constructed based on cladistic analysis. They can be phylograms when presenting non-equal branch lengths to convey the inferred degree of relatedness among the groups presented. Or they can belong to other types of phylogenies (non-cladistic) if they include different components of the evolutionary history of organisms such as estimates of diversity, enrichment or depletion of species, absolute time, biogeographical relations, and the direction of evolutionary change, in addition to genealogy. These factors provide richer information about organisms than a cladogram sensu stricto. Museums extensively use these representations.

From all this startling variety of representations of the evolution of lineages, we are mostly concerned with "traditional trees of life," mainly because many of these images are far from Darwinian (moreover, the shape of a real "tree" can unwittingly misrepresent evolutionary relationships) as well as modern images whose design might inadvertently lead to non-scientific notions.

Where Did the Image of the "Tree of Life" Come

From, How Did It Become so Widespread, and What Kind of Notions Does It Convey?

One of the most fundamental concepts of Charles Darwin's argument was that species share a common origin from a single ancestor and have subsequently diverged through time. In the fourth chapter of the Origin, Darwin included a picture that he used as an argument and as an evidence of this notion. The resulting line-diagram is an abstract and irregular design, not a tree in a literal sense and not described by Darwin as such. In his subsequent books, Darwin never included a depiction of this kind. Then, why is it that, for popular accounts of evolution, the chief image in use from late nineteenth century to represent the process is that of a tree?

Darwin came to use the metaphor of a great tree to illustrate his notion of descent with modification as early as 1837 in his Notebook "B". There, he describes an abstract tree with a main trunk to represent links of ancestry for every species and side branches which ramify further or die out to represent species divergence and extinction. Therefore, to many, the "tree of life" has its roots in one of Charles Darwin's diagrams and thus represents one of his legacies. "Charles Darwin sketched the branches of a tree in one of his notebooks to illustrate the idea that all life forms branched out from a common ancestry. Since then, the tree of life image has persisted as an aid to understanding evolution"2.

Yet history tells us that Darwin's image was not the one in everybody's mind until the middle of the twentieth century, as it was only in 1960 that his personal notes began to be printed.

It was Ernst Haeckel, a German naturalist, who published in 1874-in his book Anthropogenie - the image that became iconic of evolutionary theory in the popular realm (Fig. 1). Haeckel's now famous motif-Systematischer Stammbaum des Menschen - explores the evolutionary history of man. The most fascinating aspect of this image is that it is a real tree-a twisted European Oak with bark and leaves. Popularly, it is assumed to represent an upward journey of life from the most primitive beings at the bottom to the most advanced at the top - man at the summit of all life- even though, to Haeckel, it was a direct chain of human ancestors.

Thus, Haeckel's Stammbaum des Menschen is the source image for most of the subsequent representations of evolutionary trees in the popular sphere. Not Darwin's linediagram of the Origin - in which no single species at the end of the lines can count as a clear culminationand especially not Darwin's 1837 ink sketch-which many scholars have described as Darwin's first evolutionary tree.

In the popular realm, Haeckel's tree took over Darwin's 1859 descent diagram. But it was taken out of context. It was assumed to represent a complete evolutionary treetherefore the popular term "Tree of life." From this approach, Haeckel's Stammbaum des Menschen is clearly embedded with non-Darwinian accounts of evolution and also prejudices assumed to be inspired by the prevailing social and philosophical beliefs. The image of a real tree mightily growing upwards offered a view of evolution as a progressive and goal-oriented process that culminates in the appearance of human kind. Moreover, the conflation of religious connotations powerfully embedded in the tree

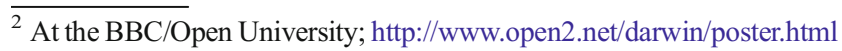


image led to interpretations that modern living beings can be less and more evolved and that the whole process was intended to "produce" human beings.

In the early twentieth century, due to the continuing effort to promote the idea of evolution in layman, evolutionary trees inspired by Haeckel's started to appear in works aimed at a more popular audience, and their inclusion eventually became standard in biology textbooks (Figs. 2 and 3). Some natural history museums also used them as a new way to explain the organic world through the lens of evolution (Fig. 4). Thus, at least in their beginning, evolutionary trees in the popular sphere were not just
Fig. 1 Haeckel's

"Systematischer Stammbaum des Menschen", 1874

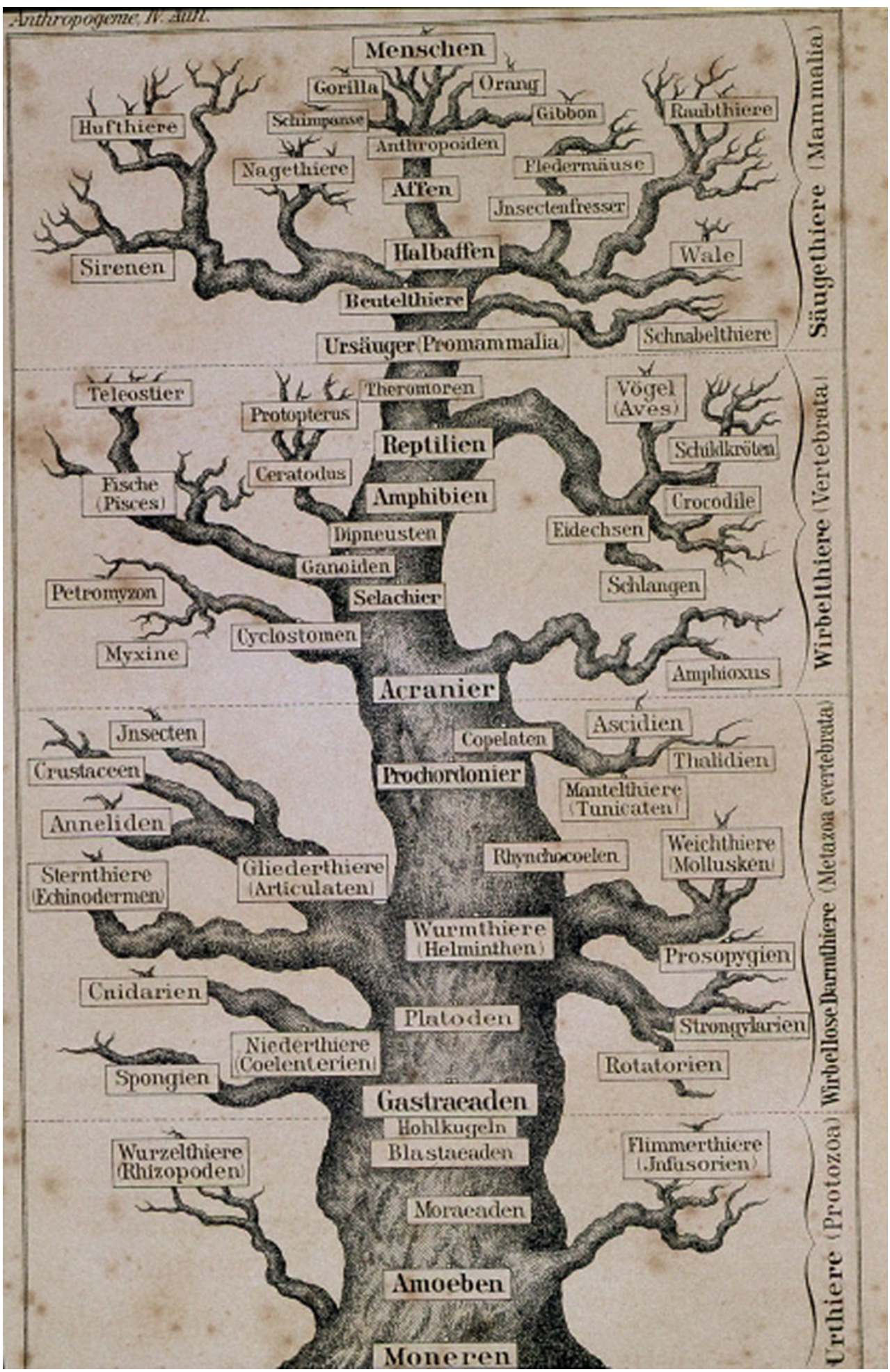


Fig. 2 Kerfoot Shute's "Evolution of Man," in A First Book in Organic Evolution, 1890

\section{EVOLUTION OF MAN.}
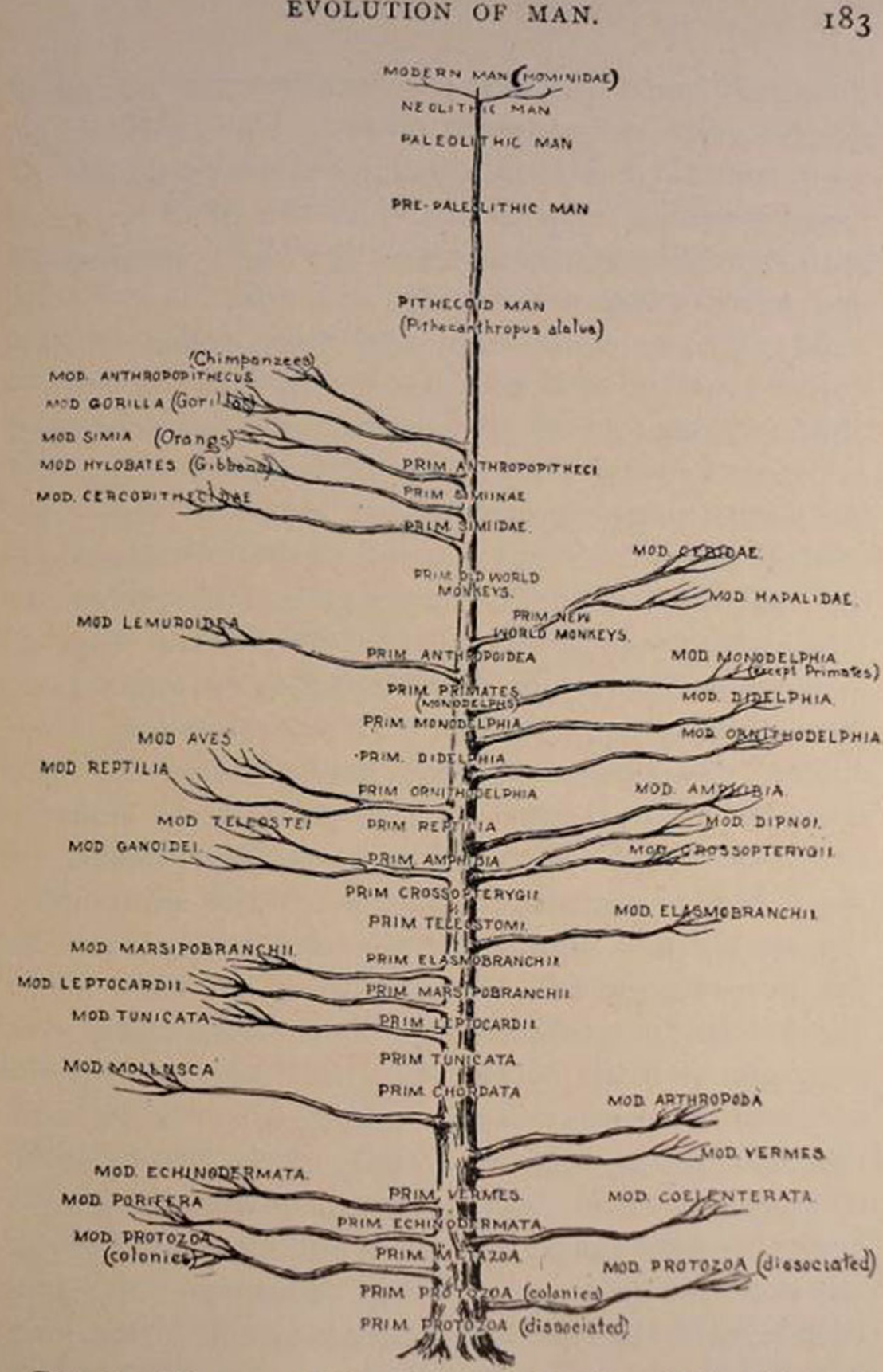

FiG. 18.-Diagram of Development: Portion of the "Tree of Life," showing approximately the relative places of the great groups of animals. The Central Trunk and Primary Branches represent Primitive (geologic) forms; the Terminal Twigs represent Modern forms. embodiments of interpretations of the theory of evolution. They enfolded deeply embedded Western preconceptions of how the world was thought to be according to religious views and other pre-evolutionary views of organic relationships.
By the turn of the century, natural history museums witnessed great changes. For many, a crucial event was the celebration of Darwin's bicentenary in 2009. Several brand new exhibits of evolution were opened, and outdated ones were overhauled. Today, evolutionary theory is at the heart 
Fig. 3 "The Ancestral Tree," Smallwood, Reveley, and Bailey, Elements of Biology, 1948

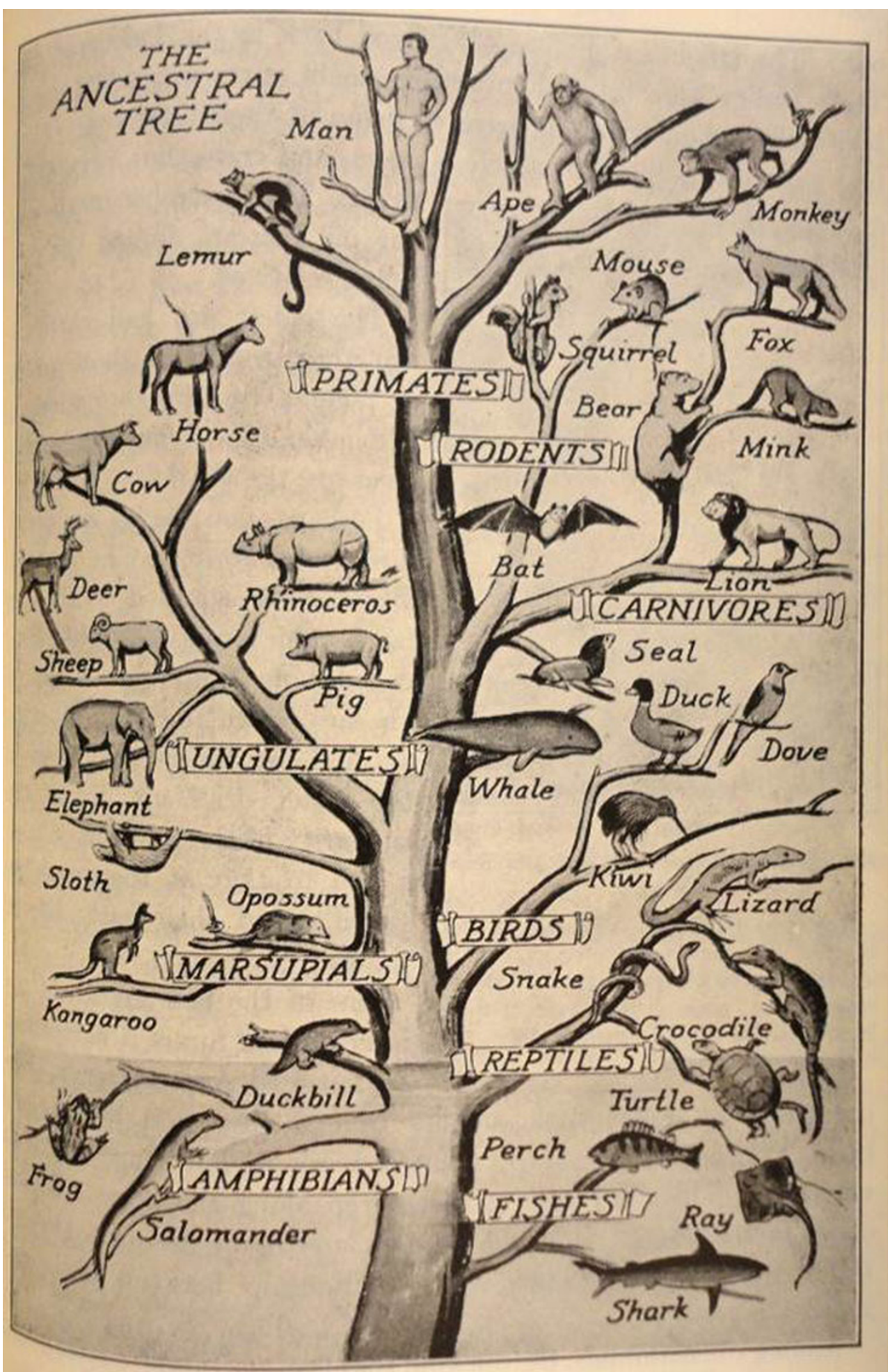

of most of them. Thus, scientific illustrators and museum displays are making real efforts to change the public perception of evolution. As the metaphor of branching and rebranching to represent the complexity of the natural world proved to be incredibly fecund for practicing biologists and for the general public, in order to distance evolutionary diagrams based on scientific evidence from traditional "tree of life" connotations, the use of cladograms became a common practice from the decade of 1990, and alternative geometries are beginning to appear.

However, even though today it is difficult to find a traditional "tree of life" (inspired by Haeckel's) in natural 
Fig. 4 'Tree of Life', in Mexico City's Geology Museum from the decade of 1980's (no longer in exhibit)

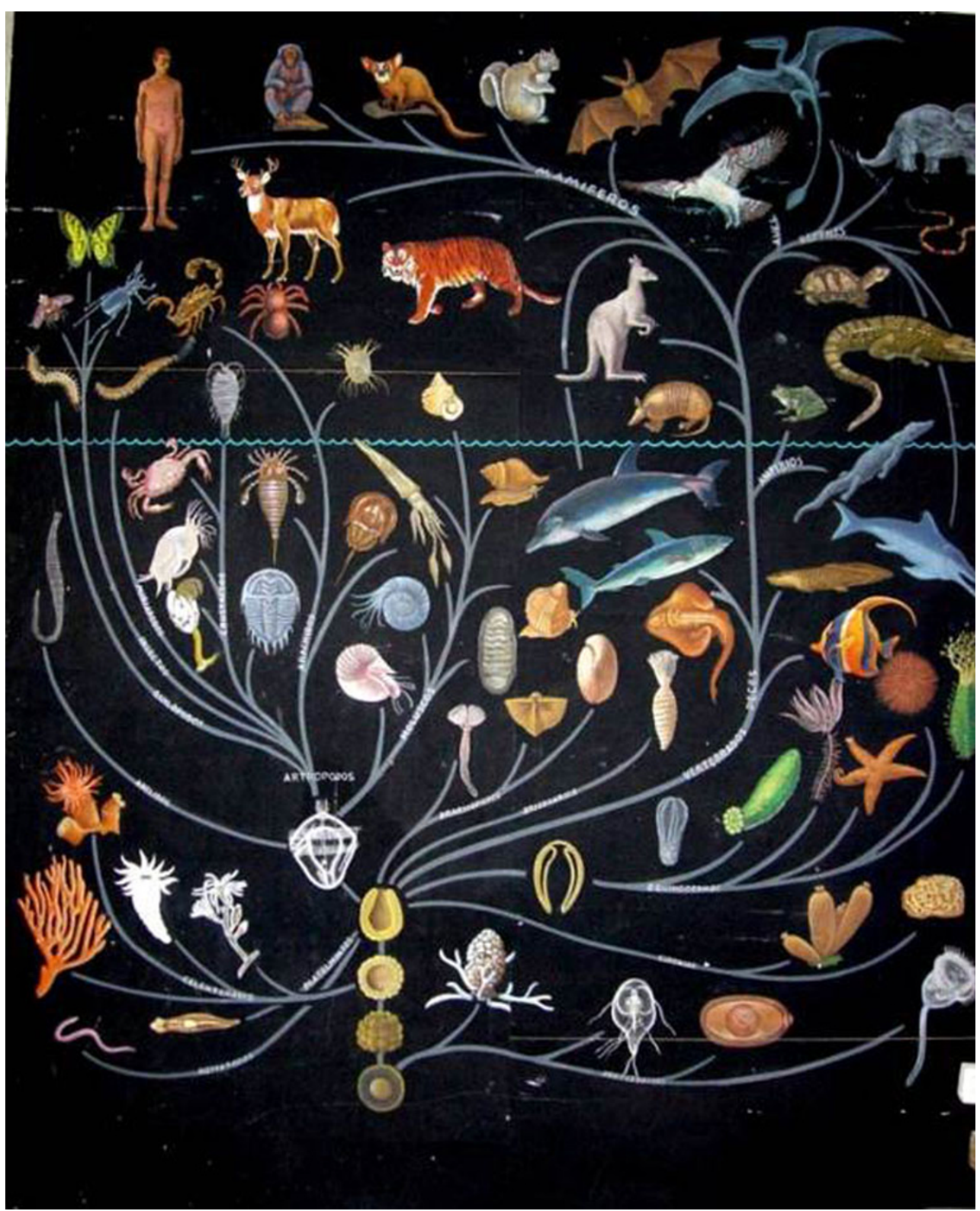

history museums, they are still present. Also, the design of many evolutionary trees is still prone to confuse the audience. Below, we revise the most fundamental misunderstandings about trees. Some of them are caused by a lack of phylogenetic literacy, but others are a direct consequence of the design of evolutionary trees (shape, orientation, and organisms presented). Later, we will discuss our findings in five important Western natural history museums.

\section{Problems of Interpretation}

Being the direct representation of evolution, evolutionary trees or phylogenies are a central element of modern biology. Tree thinking (the ability to understand evolution as a process of branching and rebranching) among the public in general, however, is not as accepted and widespread as one might expect. "Tree thinking is very much an acquired ability which needs extensive training" (Sandvik 2008), and even graduate students and professors of biology find it difficult to correctly interpret a simple tree drawing (Baum et al. 2005; Bishop and Anderson 1986; Diamond and Scotchmoor 2006; Meir et al. 2007a). There are at least three reasons for this absence of tree thinking: a general misunderstanding of the theory of evolution; a lack of familiarity with phylogenies; and a visual evolutionary culture which sustains an eminently progressive discourse full of prejudices that leads to wrong interpretations of the process (i.e., the widespread presence of traditional "trees of life"). 
According to many authors, but summarized by Gregory (Gregory 2008), the following ten misunderstandings about trees are the most significant and pervasive among non-specialists:

1. Evolution is a goal-oriented process and a linear transformation from less to more evolved organisms: Homo sapiens. This means that lay audiences tend to read trees as if they were a march of progress depicting less evolved organisms either at the bottom or at the far left side and more evolved organisms at the top/far right side.

2. There is a main line in evolution. Progressionist interpretations of evolution are hard to eradicate, and even the diagram of a tree is normally read as representing a main story (normally the one of human being or primates) with all other lineages branching off from this line sometime in the past. This problem arises specially in unbalanced and ladderized trees.

3. Reading across the tips. No matter how meticulous and elaborate a ramified diagram is, most people tend only to look at the tips and derive wrong conclusions on what is represented: The group of species at the far left is thought to be more primitive and closely related to the next at its right and so on.

4. Similarity versus relatedness. Non-specialists normally do not identify the clades depicted in trees and pay attention only at terminal nodes to conclude that trees convey relations of similarity instead of evolutionary relationships.

5. Sibling versus ancestor. The ancestor of two modern groups was or must have been very similar to one of the modern groups.

6. Long branches imply no change or an ancestral species. Many people tend to misinterpret the length of branches as if they mean the extent of change. Long branches therefore are thought to represent "ancestral" species or species similar to the ancestor who did not diversify or "kept evolving."

7. Different lineage ages for modern species. To evolutionary biologists, any modern species have been evolving for exactly the same amount of time since their divergence from a distant common ancestor. However, there is a tendency to interpret that there are lineages "more" or "less" evolved than others.

8. Backwards time axes. For lay audiences, it is common to interpret the time in the wrong way, whether from left or right (therefore assuming species at the far left to be less evolved or primitive) or from the leftmost tip to the root.

9. More intervening nodes equals more distantly related. Some people think the higher the number of internal nodes between groups of species the more distantly related they are instead of considering the number of shared ancestors.
10. Change only at nodes. Nodes represent an event of speciation but change can occur before, during, and after that particular time.

\section{Evolutionary Trees in Museums}

What Should Be Expected from an Evolutionary Tree in a Museum?

As stated before, tree thinking cannot be taken for granted, and some phylogenetic literacy is needed to derive a proper understanding of evolutionary trees. The role of an evolutionary tree in museums should be (apart from showing the evolutionary relations among sets of species per se) to serve as a tool to help people understand the connections between species that are being proposed, that is, to enable the teaching of the basics in phylogenetic literacy, by taking into consideration that some visual embodiments are prone to reinforce misunderstandings.

Museums should carefully design their evolutionary trees. They should consider the common preconceptions visitors often bring, many of them as a direct result of more than a 100 years of visual culture which has reinforced the notion that evolution is oriented from simple toward complex organisms communicating the idea of a single ladder of life amidst the extraordinary diversity of organisms - and that humans are at the pinnacle of the evolutionary story. These preconceptions may also be reinforced by the form, shape, orientation, or the group of species shown in modern phylogenies.

In this context, the authors decided to determine by observation if graphic elements within evolutionary trees in some natural history museums are more likely to reinforce rather than amend misinterpretations.

\section{Our Study}

There is a previous important study conducted by Teresa E. MacDonald (2010) which explored the use of evolutionary trees in exhibits across 207 informal science institutions and analyzed the form and content of 185 trees. This study was carried out in settings from English-speaking countries (mainly the U.S., UK, Australia, Canada, and New Zealand).

Due to the comprehensive nature of McDonald's study, the authors decided to focus on five important western natural history museums: Museum für Naturkunde, Berlin; British Natural History Museum, London (Our place in evolution exhibit); American Museum of Natural History, New York (Hall of human origins and Hall of biodiversity); Museum d'histoire naturelle, Paris (Grand Gallery of Evolution and Gallery of Compared Anatomy and Paleontology), and Museo de Historia Natural, México City (Evolution exhibit). Each museum was chosen according to its importance for the 
establishment of scientific groups, its leadership in museographic techniques and its relevance in education and research locally and globally.

The fundamental aspect taken into account in this study was the presence of graphic elements within evolutionary trees that have the potential to reinforce misconceptions. We focused on three particularly problematic characteristics of evolutionary trees:

1. Form and orientation (directionality). Ladderized and unbalanced trees in the form of a cone (classical tree oriented vertically and upward) are prone to progressionist and teleological interpretations, more so if humans or primates are localized at the upper, or at the last right tip of the tree (so that evolution looks as if it occurs teleologically or linearly towards a human goal).

2. Representation of ancestors. One common misunderstanding derived from trees is to assume that intermediate forms such as Archaeopteryx or Ambulocetus are the ancestors of birds and whales, respectively, or that there are "missing links" in the "evolutionary ladder." This is an error, as there is not enough evidence to sustain whether these ancient species were actual ancestors, a complicated sister group, or extinct species who left no descendants. Therefore, we searched for the inclusion of identified intermediate forms in internal nodes (internal nodes methodologically represent hypothetical common ancestors).

3. Depiction of time. Time is a fundamental and difficult concept in understanding evolutionary trees. Due to the tendency to map temporal increases horizontally on diagrams, non-specialists have difficulty understanding the moment of appearance of lineages (McDonald 2010), particularly when evolutionary trees do not explicitly label time.

The authors also looked for traditional "Trees of Life." These are contemporary representations of Haeckel's tree of 1874. These sorts of trees show evolution as a progression from simple to complex with a distinctively teleological perspective (Bishop and Anderson 1986).

Taking the previously described aspects into consideration, out of the nearly 300 evolutionary trees present in the studied museums $(\sim 270$ in the AMNH; $\sim 10$ in the natural history museum of Berlin; five in the natural history museum of Mexico City; six in Our place in evolution Galley at the natural history museum of London, and two in the Great Gallery of Evolution in Paris), we localized 13 evolutionary trees which might be particularly problematic (see Appendix) and three images that are useful to overcome the pitfalls previously described (see Appendix).

\section{Exhibiting the Tree of Life in Five Important Western Natural History Museums}

\section{An Overview}

The British Natural History Museum and the American Museum of Natural History's evolutionary exhibits rest upon phylogenetic analyses, therefore the main theme for these evolution exhibits is systematics. Cladism is the backbone of New York exhibits, and cladograms are abundant in London in Our place in evolution, which - by means of such trees-explores the characteristics humans share with chimpanzees and gorillas and how humans are related to other apes, living and extinct.

For the Great Gallery of Evolution of Paris, what is important is to show the result of evolution, that is, the biological diversity of our planet, as well as the evolutionary mechanisms behind it. The museum opted to present a universal phylogeny in the form of the three domains proposed by Carl Woese. The main purpose of this tree is to enable visitors to understand that all life is related to a universal ancestor and to give perspective to the relative importance of different organisms. One can see that animals are just a tiny twig recently evolved compared with other eukaryotes.

The Museum of Natural History in Berlin houses one of the most modern evolution galleries of all. Evolution in action opened in July 2007, and it is influenced by current trends in evolutionary science and by contemporary styles of exhibit design. Employing stuffed specimens, interactive and virtual exhibits, fossils, and so forth; it engages visitors with the mechanisms of evolution.

Germany was the birthplace of the famous scientist and illustrator Ernst Haeckel who popularized the image of the tree of life as the iconic image for evolution. Possibly that is the reason behind the numerous evolutionary trees that can be found in this museum, one of which is especially interesting as it employs high technology to present an interactive "complete" 3 tree of life with the information made available by the Tree of Life Project Organization.

The Museum of Natural History of México City has a few evolutionary trees, none of which is accurate as they were conceived as merely decorative. Surprisingly, there is a "march of progress" depicting the evolution of horses even though it is an outdated image which promotes several misconceptions such as the notion of progress in evolution and a hierarchy from simple to complex forms in terms of less and more evolved.

\footnotetext{
${ }^{3}$ Resolving the Tree of Life is among the most complex scientific problems as it is almost unimaginably vast. When we say a "complete" tree of life, we mean a tree showing most of the organisms that have been discovered and described and for which evolutionary relationships are known.
} 


\section{Evolutionary Trees in Natural History Museums Prone to be Misunderstood}

Following, we present a tabular summary of: (1) the graphic elements that have to do with the design and visualization of evolutionary trees that might lead to conceptual errors or misunderstandings; (2) the description of each element; (3) our findings in each of the five visited museums; (4) the consequences of presenting these "problematic" elements for the proper understanding of phylogenies; (5) the particular evolutionary trees inadvertently possessing the described elements; and (6) some possible ways to overcome these pitfalls.

\begin{tabular}{|c|c|c|}
\hline $\begin{array}{l}\text { Characteristics of } \\
\text { the evolutionary } \\
\text { trees }\end{array}$ & Form and orientation & Representation of ancestors \\
\hline Description & $\begin{array}{l}\text { Trees must have a main trunk, } \\
\text { a single point of inception as } \\
\text { a requirement of evolutionary } \\
\text { theory to represent } \\
\text { commonality of origin for } \\
\text { groups of related organisms. } \\
\text { This sounds like a major } \\
\text { constraint upon the geometry } \\
\text { of a tree, but the reality is } \\
\text { that "the geometric } \\
\text { possibilities of evolutionary } \\
\text { trees are nearly endless" } \\
\text { (Gould 1997). }\end{array}$ & $\begin{array}{l}\text { Fossilized remains of } \\
\text { intermediary forms that } \\
\text { illustrate an evolutionary } \\
\text { transition are scientifically } \\
\text { termed transitional fossils. } \\
\text { In popular terminology, } \\
\text { these amazing organisms } \\
\text { such as Archaeopteryx, } \\
\text { Ambulocetus, or Tiktaalik } \\
\text { are known as "missing } \\
\text { links" and thought to be } \\
\text { direct ancestors of certain } \\
\text { groups. From the evidence, } \\
\text { it is impossible to be certain } \\
\text { that a transitional fossil is } \\
\text { actually the ancestor of } \\
\text { any extant group. }\end{array}$ \\
\hline
\end{tabular}

Museum's findings The majority of evolutionary trees found in the museums under our study have the classic cone shape, and a great portion of them are ladderized and unbalanced. In those trees showing humans, all the cladograms exhibited, in the Natural History Museum of London in Our place in evolution and a phylogeny of primates from the $\mathrm{AMNH}$, place humans either at the top or at the upper right side. This presents the risk of leading the audience to interpret evolution moving teleologically towards a human being.

Consequences
No matter which groups of species are being represented, in these kinds of trees, the audience that lacks phylogenetic literacy will tend to assume the group at the top or at the upper right tip is the most evolved (see Sandvik 2007).
Some of the museums we visited show trees which identify intermediate forms in internal nodes. This action might inadvertently lead the audience to confuse them as ancestors.

\footnotetext{
Since evolution is a branching process, the inclusion of transitional forms in or near internal nodes of a tree gives the notion that evolution produces a ladder-like progression of forms, even though the intention might be to represent an organism near the point where individual lineages diverge. Another source of error from the inclusion of transitional fossils in the internal nodes of a tree is that such images give the impression that evolution is not an ongoing process but that it has an endpoint (namely $H$. sapiens). Evolution is actually a process that does not stop; therefore, all populations of organisms are actually in transition.
}

Depiction of time

Time is a fundamental and difficult concept in understanding evolutionary trees. Although there is a current discussion about student's interpretation of time in evolutionary trees and the benefits and pitfalls of incorporating time (Catley and Novick 2008; Dodick 2009), it has been stated that it is critical to show students what we know about the emergence of major new taxonomic groups in geologic time (Padian 2008). In evolutionary trees, time extends from the root to the terminal nodes, indicating that all of the terminal lineages or organisms are contemporary or equally modern.

Very few evolutionary trees have temporal components even though in the public mind there is a tendency to misunderstand the moment of appearance of lineages and misread the time axis on evolutionary trees. Eight out of the 13 trees we found to be problematic lack temporal components (see Dodick 2009)
Traditional "Tree of Life"

Modern interpretations of traditional "Trees of Life" are not necessarily depicted as "real trees" but show the evolutionary history of life as an upward and progressive journey from "simpler" to "complex" forms. Evolution is the ongoing adaptation to local circumstances, and every extant organism is equally modern or evolved.

Very few evolutionary trees in museums resembles Haeckel's famous (and misnamed) "Tree of Life" as these sort of diagrams "are the epitome of a teleological view of evolution: they overtly suggest the notion of direction and progress" (Catley and Novick 2008).

\section{According to Gregory (2008), it is common for lay audiences to read time horizontally from left to right, believing the organism on the left is more primitive than its cousins on the right.}

\footnotetext{
The information conveyed by these kinds of evolutionary trees might be interpreted as evolution occurring from "lower" or "less evolved" to "higher" or "more evolved" organisms even when branch tips represent equally modern sets of forms. Also, different groups of modern animals can be seen as direct ancestors of other groups.
} 
Particular trees possessing such characteristics (see figures in the Appendix)

Possible actions
Figure 5: Cladogram showing the phylogeny of primates, from Our place in evolution in the Natural History Museum, London. Figure 6a, b: Graphical hypothesis on ancestral relationships, from $\mathrm{Our}$ place in evolution in the Natural History Museum, London. Figure 7a, b: Graphical hypothesis on humans' more closely related ancestor, from $\mathrm{Our}$ place in evolution in the Natural History Museum, London. Figure 8: Humans' closest living relative, from Our place in evolution in the Natural History Museum, London. Figure 9: Primate Family Tree at the American Museum of Natural History. Figure 10: Phylogeny of vertebrates in the Museum of Natural History, Berlin.

The most important information about a tree is its topology or branching order. In order to avoid a teleological or progressive linear reading, one possible solution is to balance the tree and to rotate a few nodes so that humans are not depicted as if they were the end of the evolutionary process. This rotation does not affect the topology of the tree, so why keep placing humans or primates at the end of the sequence as if it were a march of progress or a chain of being?
Figure 10: Phylogeny of vertebrates in the Museum of Natural History, Berlin. Figure 11: Evolutionary tree of vertebrates in the Museum of Natural History, Berlin. Figure 12: Evolutionary tree of reptiles, in the Museum of Natural History, Mexico City. Figure 13: Evolutionary tree of Mammals, in the Museum of Natural History, Mexico City.

Providing the basics for tree reading suggests that the use of evograms (evolutionary diagrams integrating different lines of evidence) reflects more accurately and integratively how scientists know what they know about the major changes in evolution. In evograms, "taxa are compared in an explicit phylogenetic context. The transformation of homologies is indicated and explained in the figure's caption. Functional changes are clarified. Extinct animals are no longer seen as direct ancestors of each other (missing links), but rather as representatives of tree of life" (Padian 2008).
Figure 5: Cladogram showing the phylogeny of primates, from Our place in evolution in the Natural History Museum, London. Figure 6a, b: Graphical hypothesis on ancestral relationships, from Our place in evolution in the Natural History Museum, London. Figure 7a, b: Graphical hypothesis on human's more closely related ancestor, from $\mathrm{Our}$ place in evolution in the Natural History Museum, London. Figure 8: Human's closest living relative, from Our place in evolution in the Natural History Museum, London. Figure 12: Evolutionary tree of reptiles, in the Museum of Natural History, Mexico

City. Figure 13: Evolutionary tree of Mammals, in the Museum of Natural History, Mexico City.

Stress how time axis should be read or place a timeline for the events represented.
Figure 14: "Tree of Life" from the Natural History Museum, Mexico City. Figure 15: "Tree of Life" from the Great Gallery of Evolution, Paris.

To avoid this sort of tree whatsoever.

\section{Conclusions}

Evolutionary trees are of fundamental importance in evolutionary exhibits. They convey the process which has brought about the startling biodiversity of our planet and help people understand the connections among living and extinct species. Nonetheless, they are not easy for lay audiences to understand. Several core aspects of evolution such as adaptation and natural selection are non-intuitive. Moreover, there are several intuitions like teleology and essentialism, which originate in childhood and persist into adulthood. These intuitions generate preconceptions that interfere with the proper understanding of the theory of evolution.

Albeit many of the problems and misconceptions regarding evolutionary trees are a consequence of a poor understanding of the most important components of phylogenies - and their underlying concepts - due to the lack of a proper education, an important source of misinterpretations comes from the design and visualization of the trees. Some tree incarnations reinforce some of the preconceptions people bring to museum's exhibits (O’Hara 1992). 
Problems arise when, in an effort to build a bridge between science and lay audiences, science communicators select and simplify primary research (O'Hara 1992). This tendency results in one or some of the following difficulties: selective attention (there is a tendency to depict certain taxa such as primates, horses, or mammals which in the people's mind are more evolved or advanced), narrative perspective (anthropocentric trees) (O'Hara 1992), and biased series of events about the history of life (evolution as a progressive and goal-oriented process with man at the summit of all life) (Gould 1997).

For example, the idea that evolution is a goal-oriented process and a linear transformation from less to more evolved organisms is reinforced by unbalanced and ladderized trees, more so if human beings or primates are located at the far right side (Baum et al. 2005; Gregory 2008; Meir et al. 2007a; Sandvik 2007). By simply rotating some internal nodes of the tree, this problem can be minimized. But this is not only a problem of a lack of understanding of evolution but also a cultural matter as "many of the most common and potent metaphors of Western history contrast a good and moral up with a bad and reprehensible down: heaven and hell, head and feet, flowers and roots, sky and earth, sunlight and darkness. In this hoary context, it will be hard to disentangle the apparently neutral concept of evolutionary development through time from a notion of progress as the tree of life branches toward heaven" (Gould 1997). That is why "traditional trees of life" should be avoided in museum exhibits. Circular trees on the other hand have the conceptual advantage of not favoring any lineage over another. This might help overcome the tendency to read only the terminal nodes of trees as if they were a march of progress (see Gould 1997).

Cladograms in the Natural History Museum of London are an example of evolutionary trees that inadvertently might reinforce people's preconceptions about evolution. These figures show human beings at the top of the trees. It is true that the theme of the exhibit is Our place in evolution, so naturally evolutionary trees must present the most recent hypothesis on human evolution (how we are related to other apes and other hominids). However, the relevant information visitors can derive from phylogenies is in the branching order (topology of the tree), and in the sequence of internal nodes, the order of terminal branches is meaningless. Therefore, clades can be rotated without affecting the topology of the tree (Baum and Offner 2008; Baum et al. 2005; Gregory 2008). In this sense, a solution is to locate humans in the middle, between chimpanzees and gorillas, for example, and not at the top. But "unfortunately, a tendency to place humans or some other preferred taxon at the top or right of every tree appears to be an unshakable habit of many phylogeneticists, although there is no objective reason for doing so" (Gould 1997).

In the AMNH, by using cladistics as their main organizing principle, humans are placed at the middle of the halls and not at the end because primates separated rather early from other mammals.

Another important aspect of evolutionary trees in the studied museums is that there is great diversity of visual incarnations. In some cases, this is to show alternative approaches to representing the phylogeny of lineages, and in others, this is a reflection of the coexistence of modern and older exhibits (Diamond and Scotchmoor 2006).

Overall, the findings of this study show that, in the five museums studied, the traditional "Tree of Life" inspired by Haekel is minimally employed. Anthropocentrism in phylogenies is relatively common as well as several topological elements which may reinforce misconceptions about evolution (ladderized or linear depictions and a vertical-upward orientation). Also, few trees include the presence of intermediate or extinct forms which might be interpreted as ancestors (missing links), rather than representatives of the intended evolutionary tree.

Difficulties for understanding phylogenies provoked by their design and visualization must be taken into consideration. If unbalanced and ladderized trees are prone to be misinterpreted, then museums should avoid them, or otherwise include further resources for understanding them, such as additional information in the form of pamphlets, computer programs, interactive touch screens, and even websites.

As many traditionally used visual incarnations of evolutionary trees can unwittingly misrepresent evolutionary relationships (top-right placement of humans, vertical-upward orientated diagrams), today's biologists are devising new ways to overcome these pitfalls. Some of the studied museums-AMNH, the Parisian Great Gallery of Evolutionhave opted to present circular trees in order to show the amazing biological diversity of our planet - eubacterias greatly outnumber the rest of organisms. These kinds of trees have the conceptual advantage of not favoring one branch over another, therefore limiting a progressionist reading of evolution (Figs. 17 and 18).

Although more study on how people interpret and understand these relatively novel representations is needed, it is clear that, by means of different geometries, the pictorial power of trees and the knowledge of the impediments to proper understanding, museums are producing innovative representations that are improving evolutionary iconography. 


\section{Appendix}

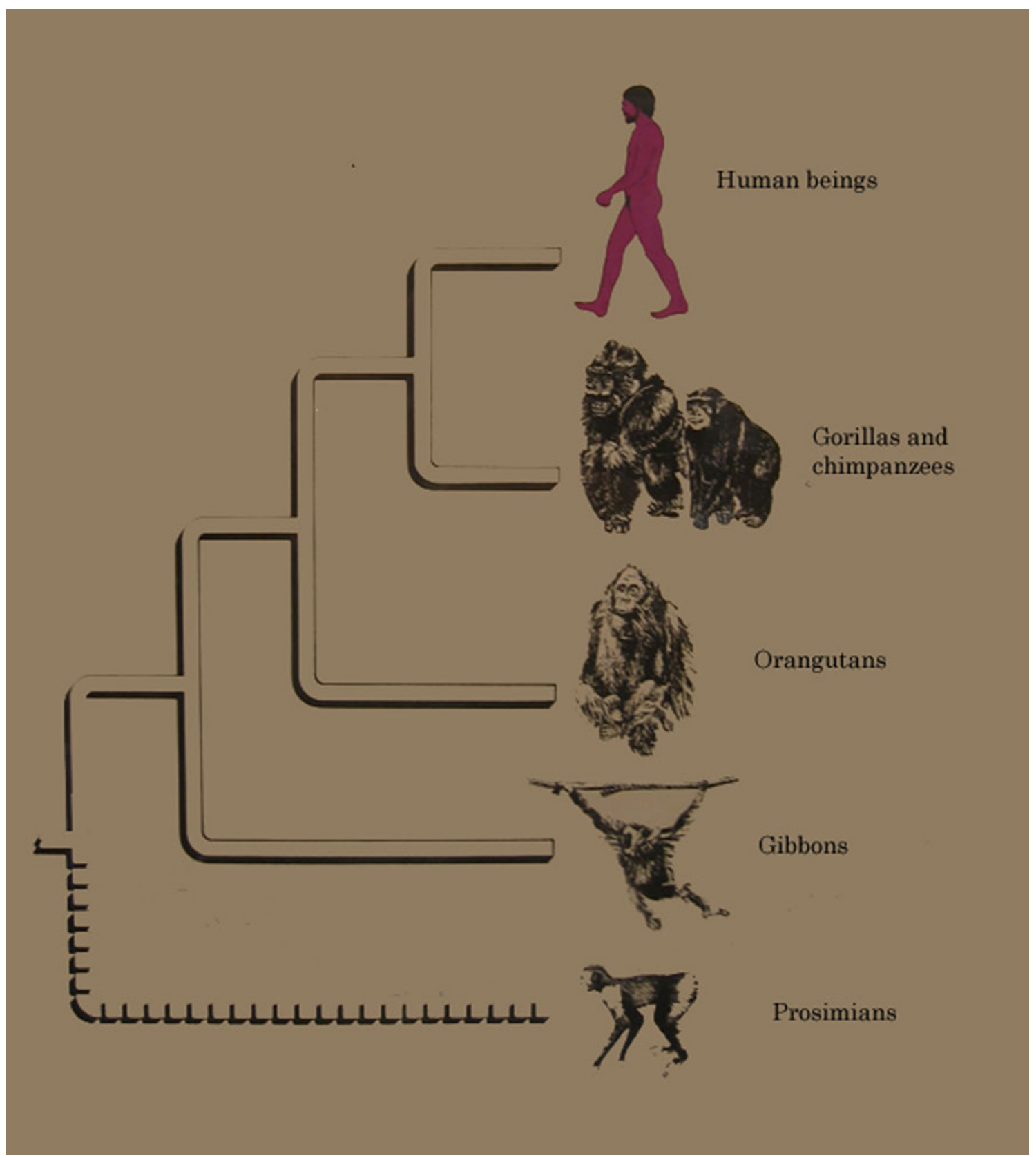

Fig. 5 Cladogram showing the phylogeny of primates, from Our place in evolution in the Natural History Museum, London 


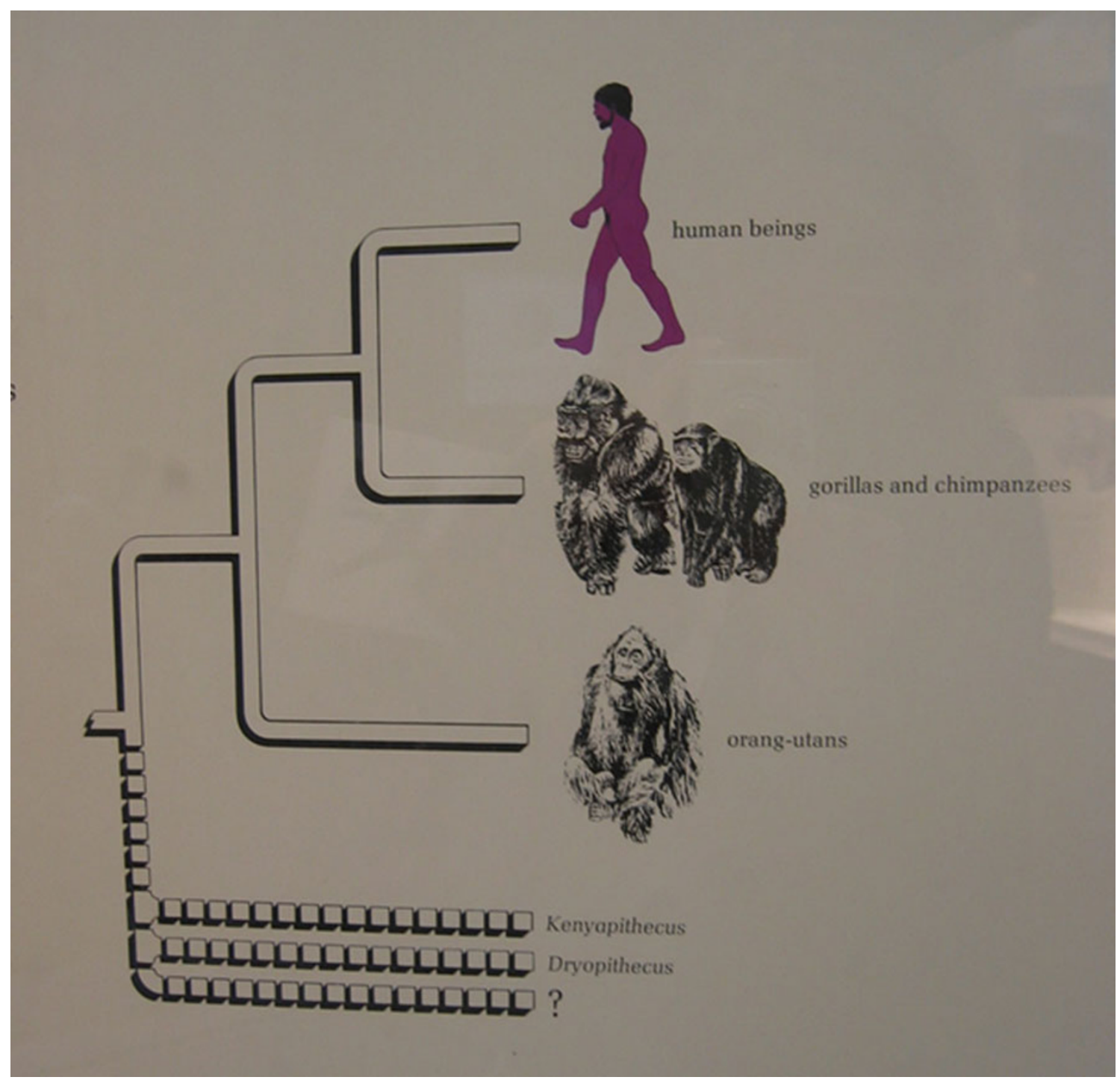

Fig. 6 Graphic hypothesis on ancestral relationships, from Our place in evolution in the Natural History Museum, London 


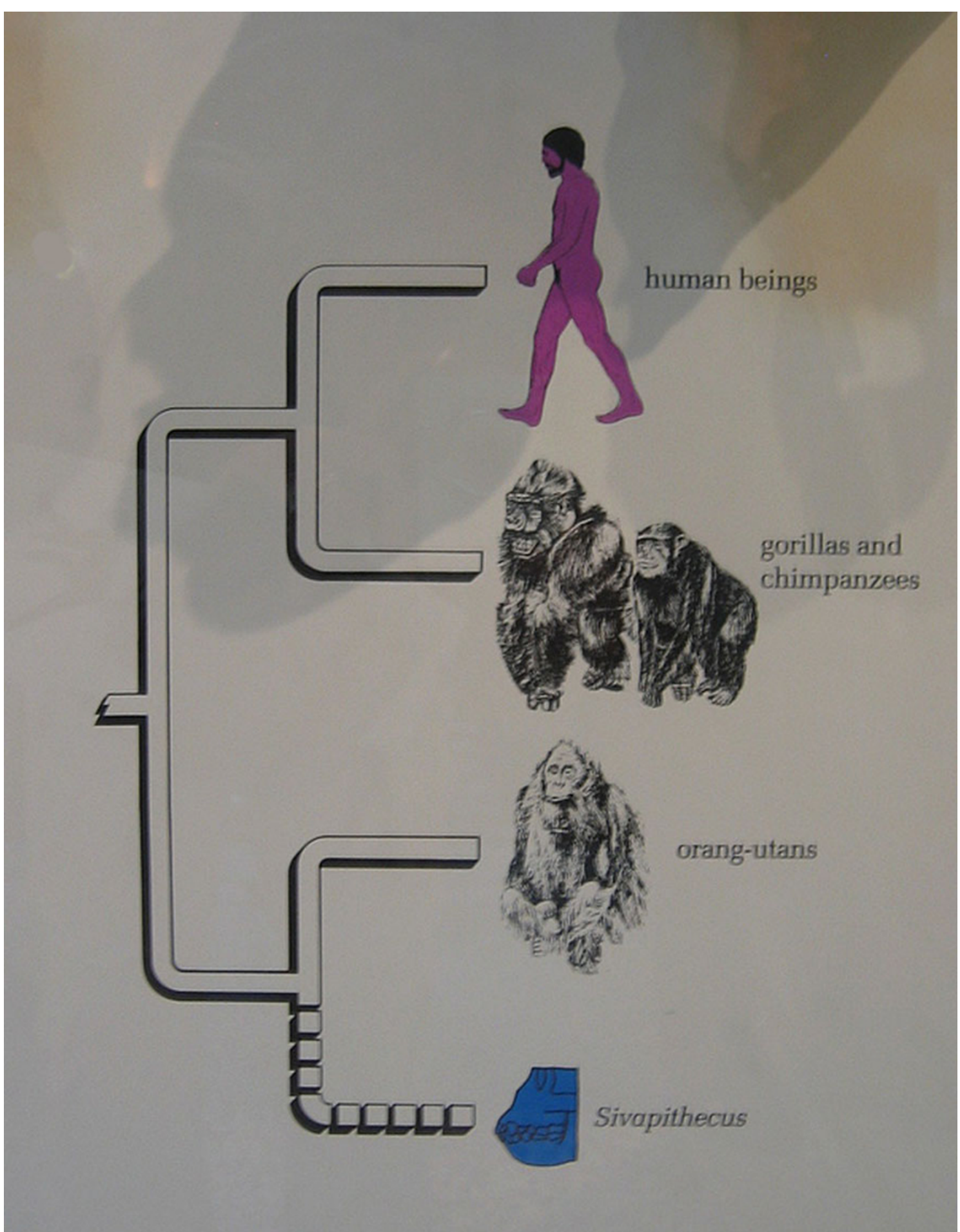

Fig. 6 (continued) 


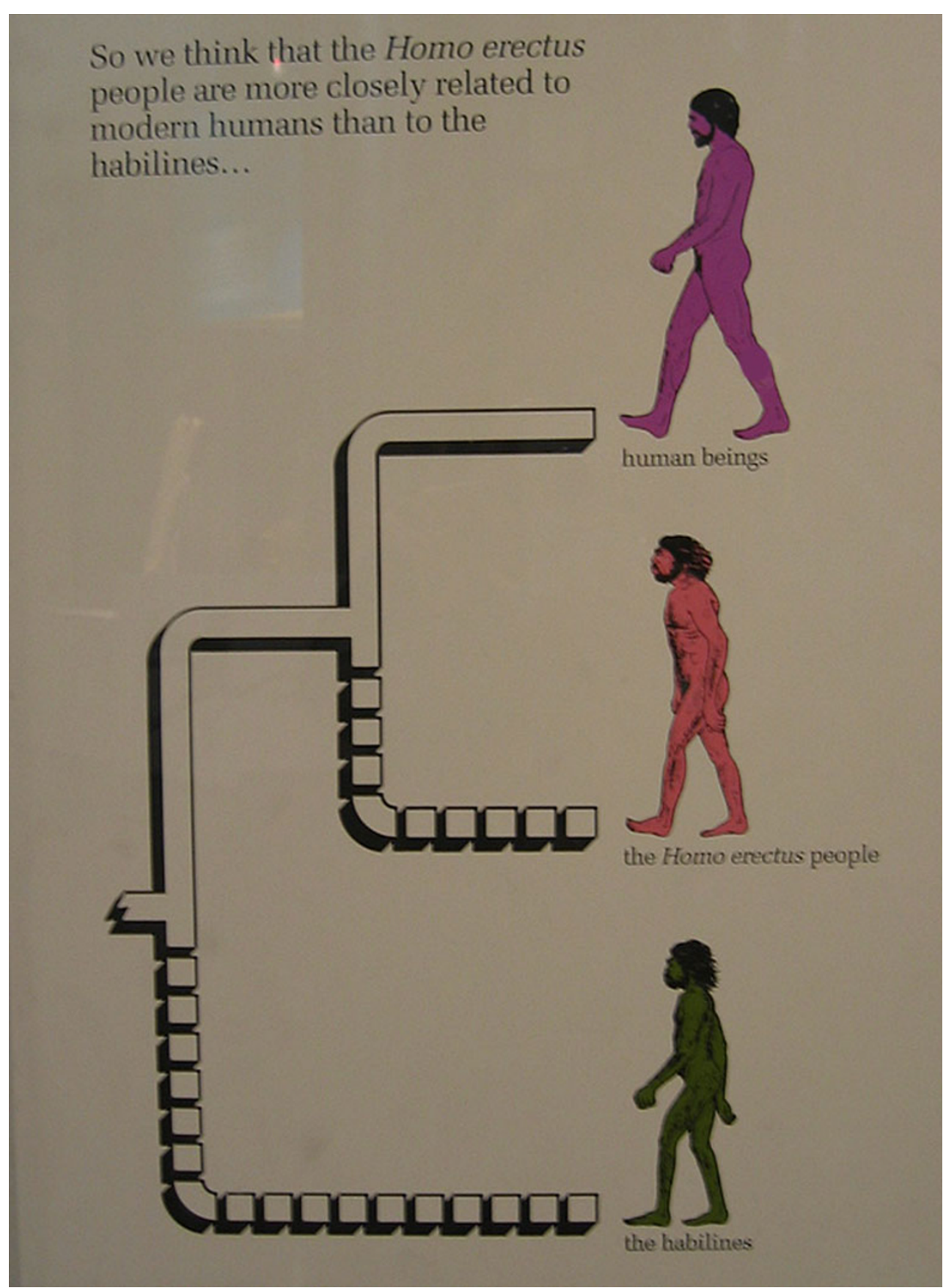

Fig. 7 Graphic hypothesis of humans' more closely related ancestor, from Our place in evolution in the Natural History Museum, London 


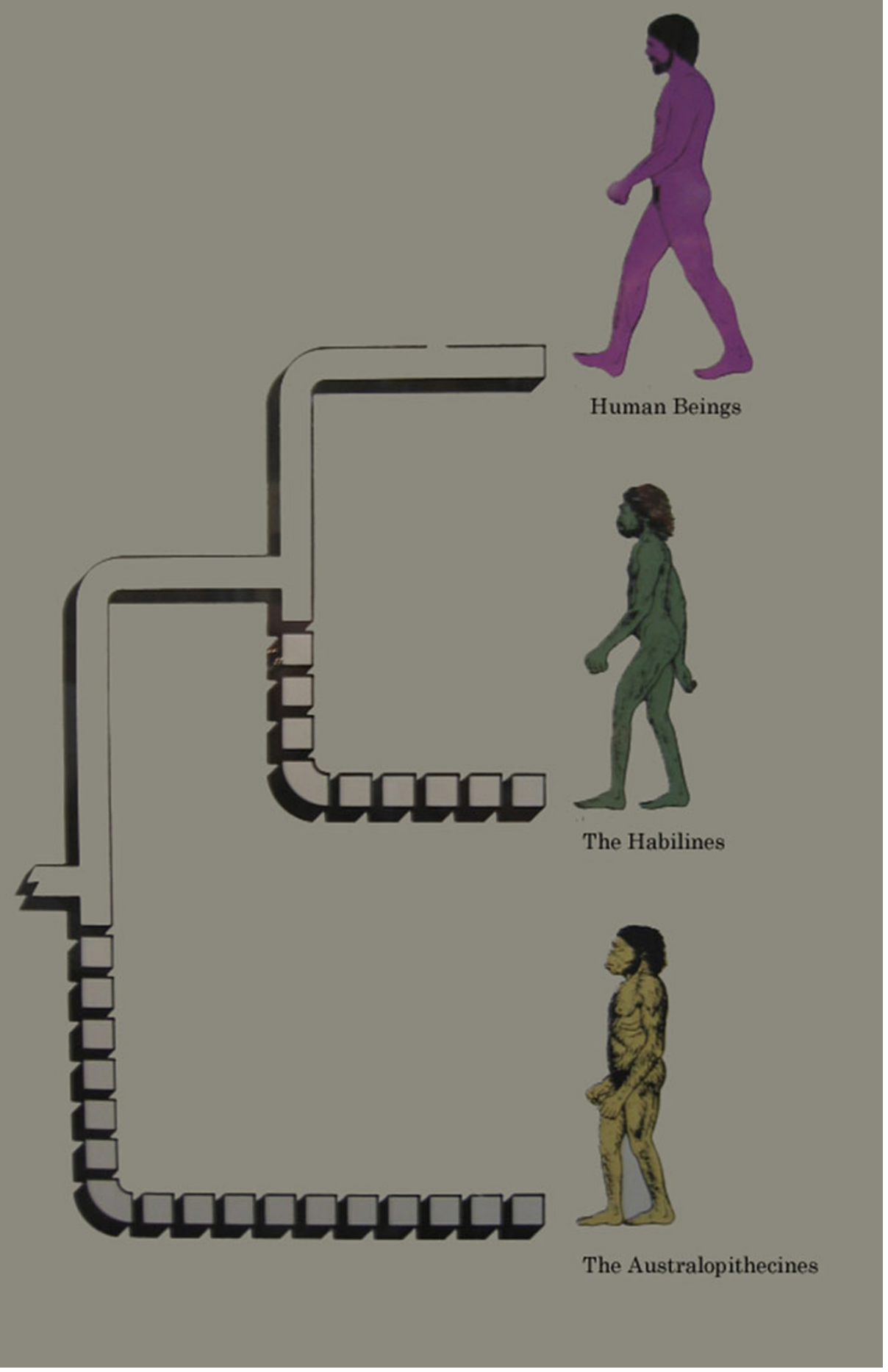

Fig. 7 (continued) 


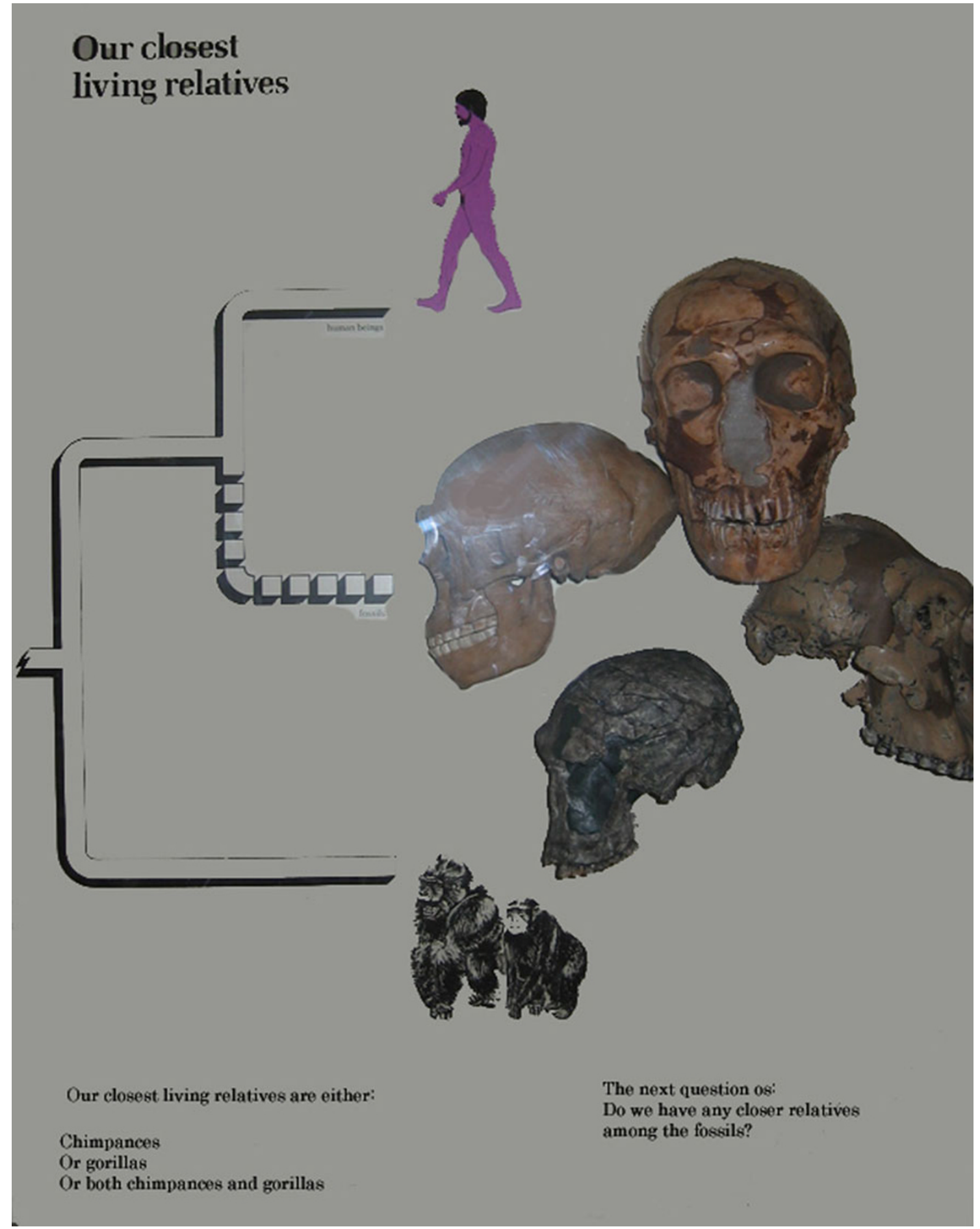

Fig. 8 Humans' closest living relative, from Our place in evolution in the Natural History Museum, London 


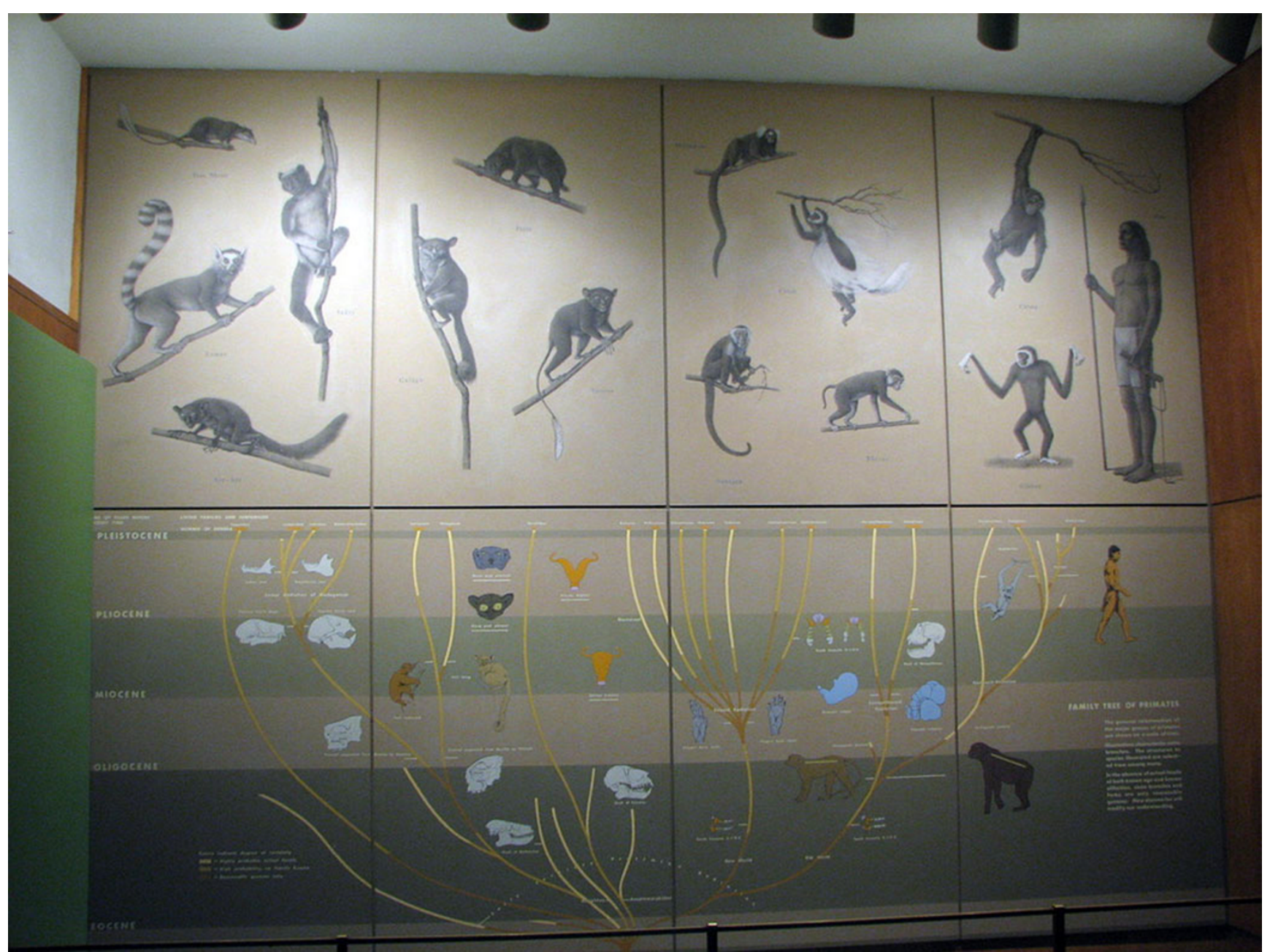

Fig. 9 Primate Family Tree at the American Museum of Natural History 


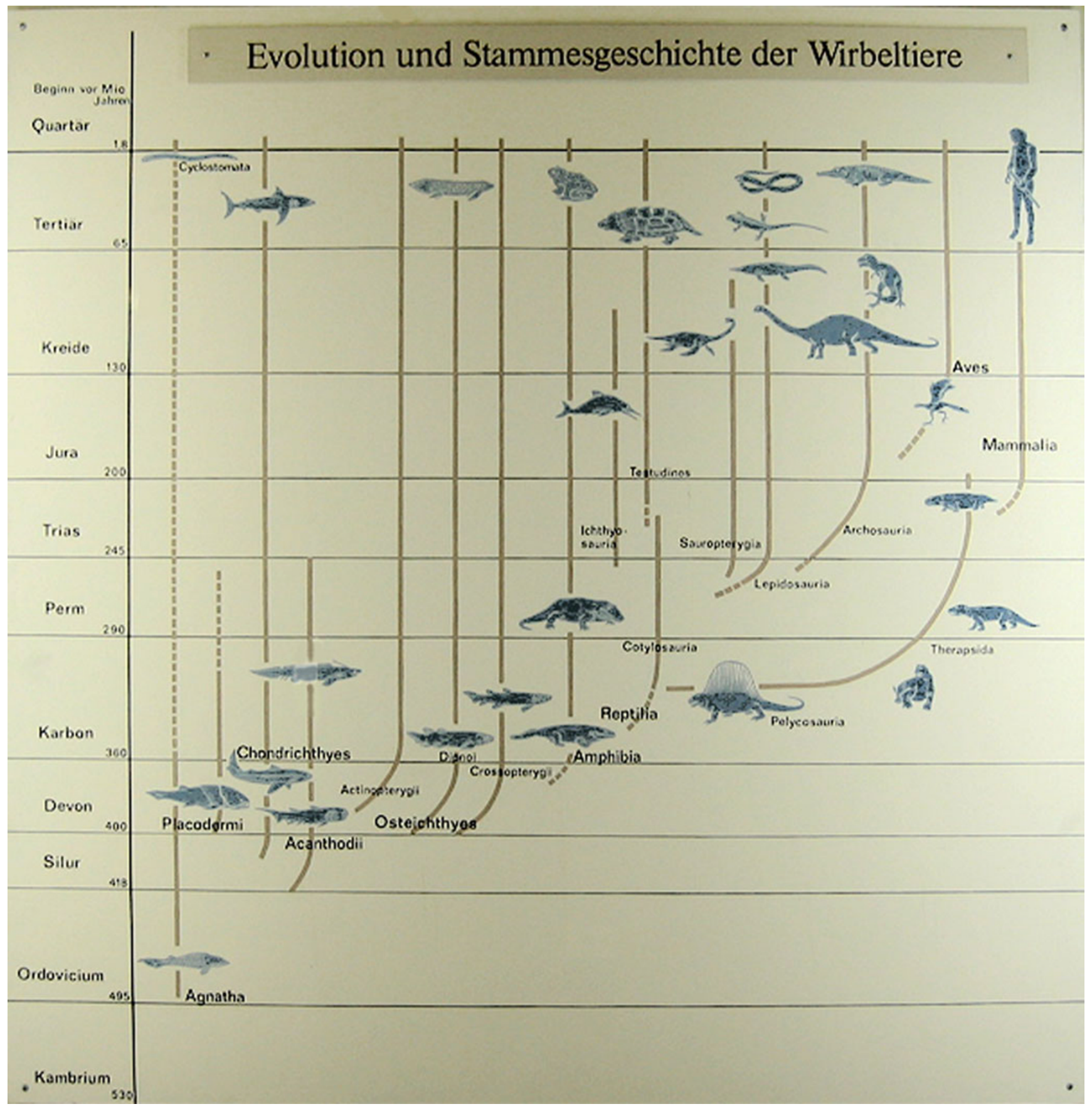

Fig. 10 Phylogeny of vertebrates in the Museum of Natural History, Berlin 


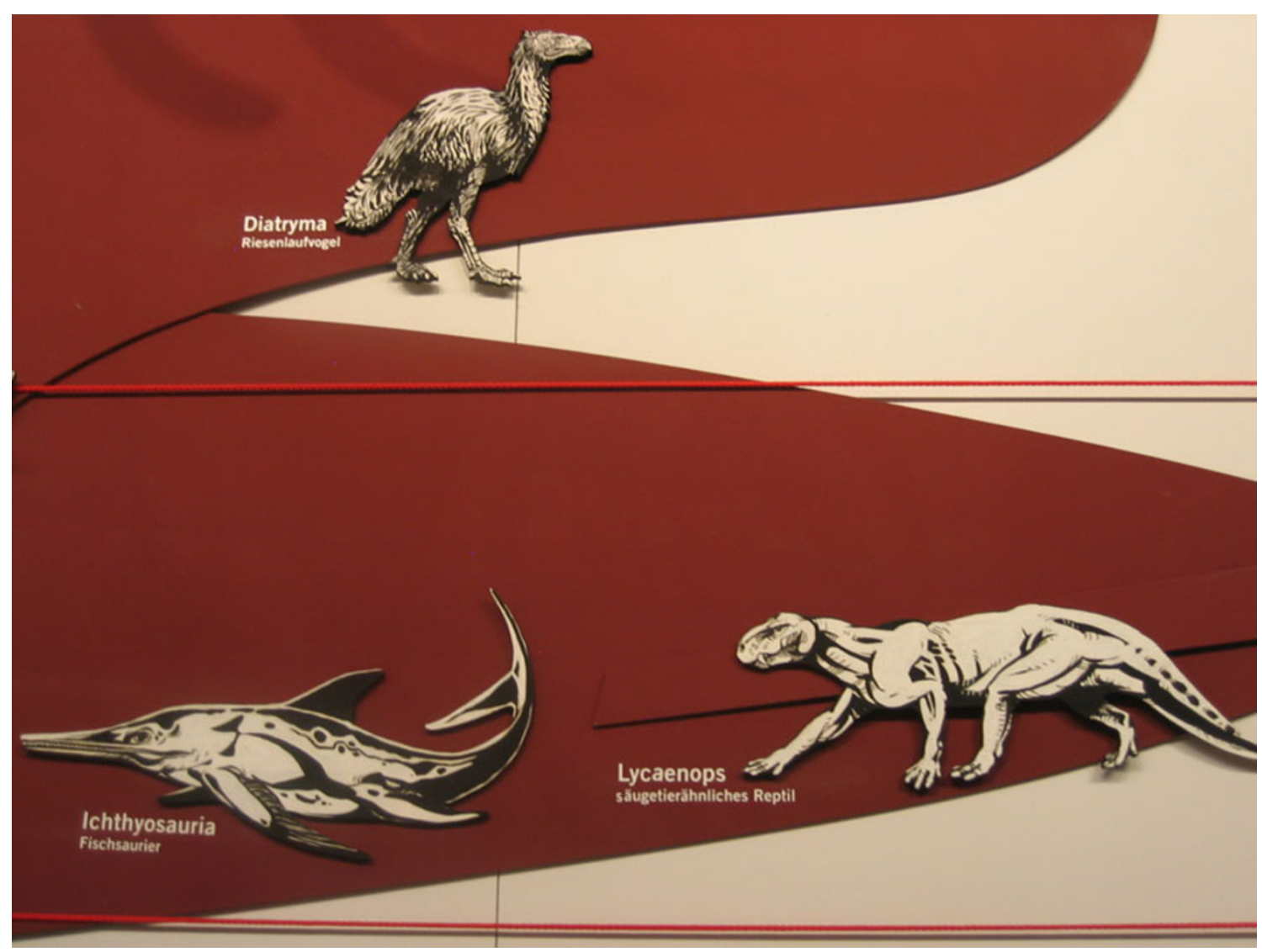

Fig. 11 Detail of another vertebrate evolutionary tree in the Museum of Natural History, Berlin

Fig. 12 Evolutionary tree of reptiles, in the Museum of Natural History, Mexico City

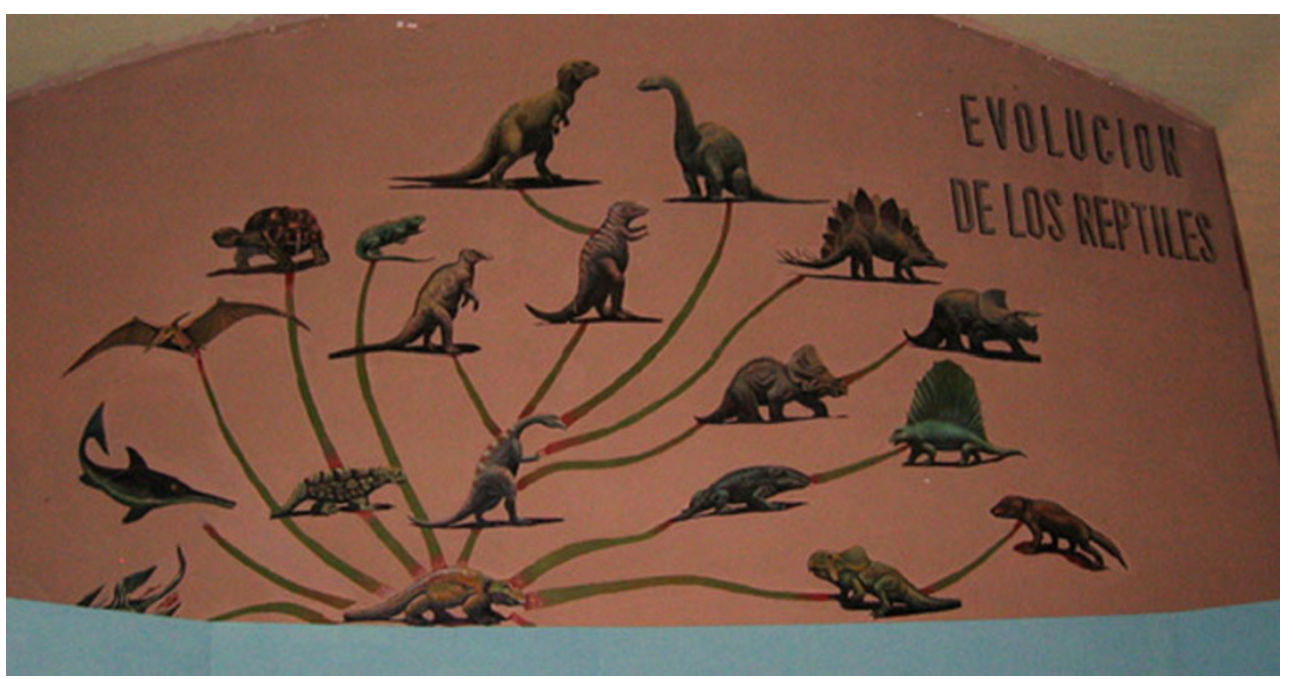




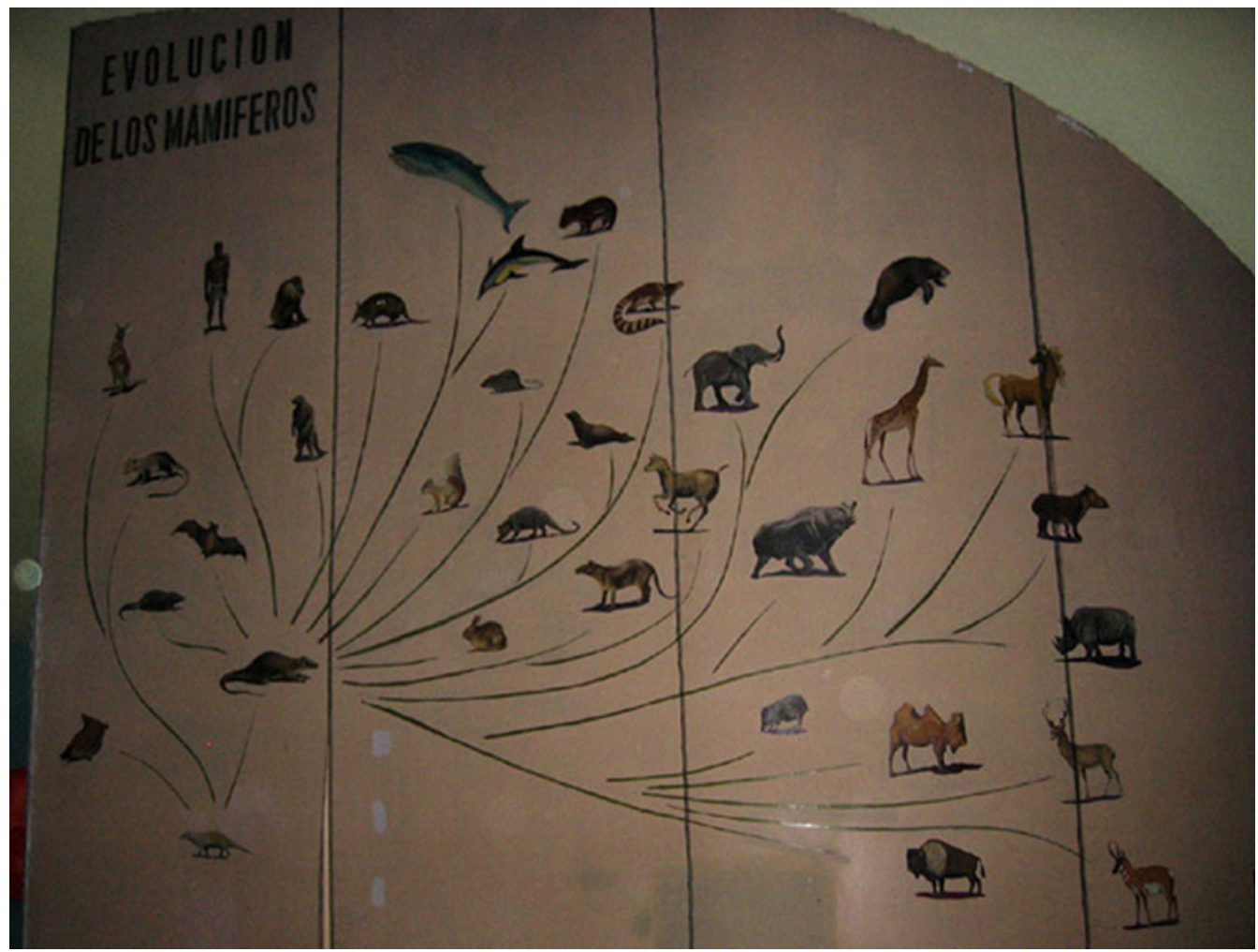

Fig. 13 Evolutionary tree of Mammals, in Mammals in the Museum of Natural History, Mexico City

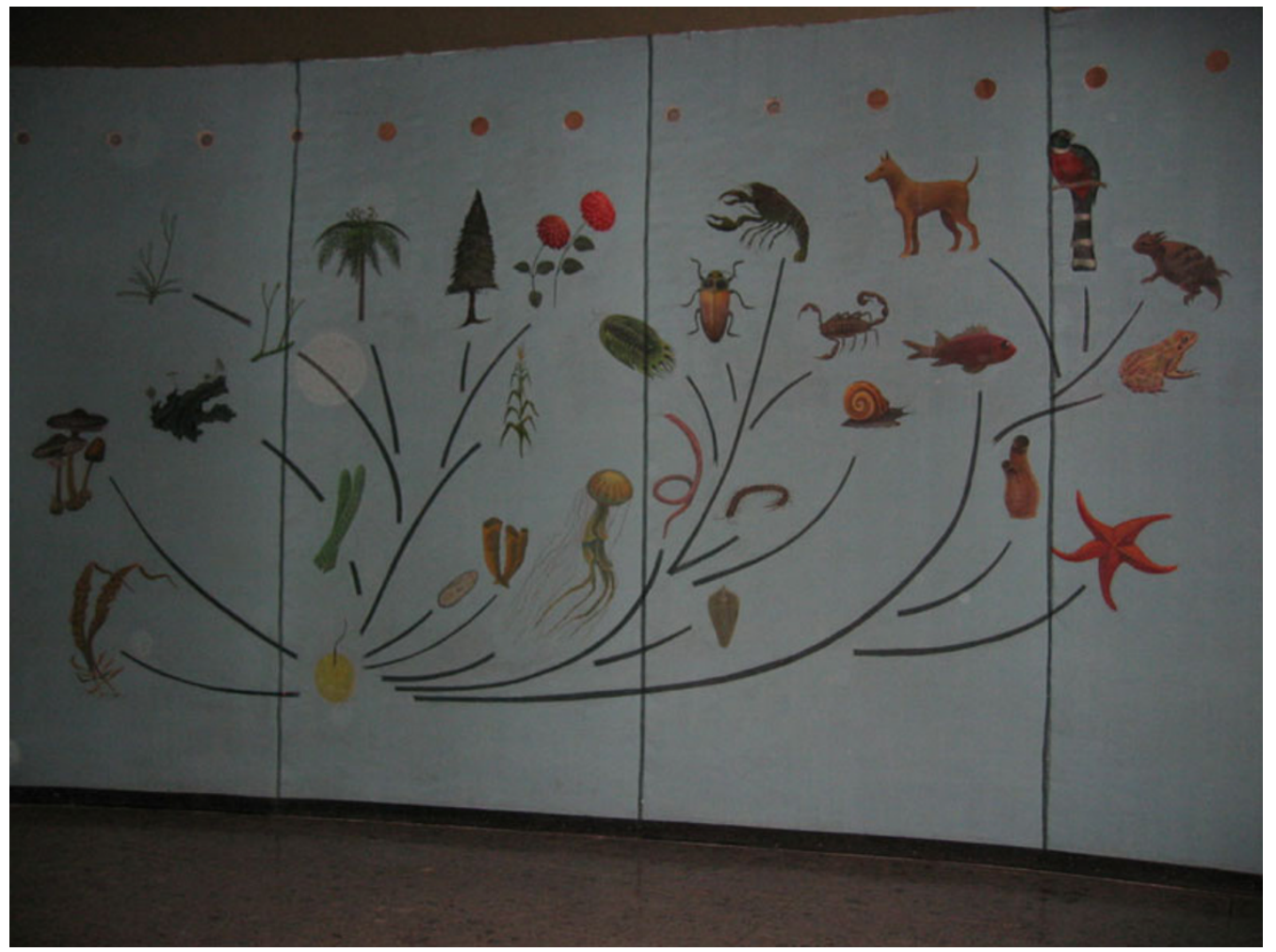

Fig. 14 "Tree of Life" in the Museum of Natural History, Mexico 
Fig. 15 "Tree of Life" at the Great Gallery of Evolution in Paris

Fig. 16 Interactive tree at the exhibit Evolution in action, Berlin Natural History Museum
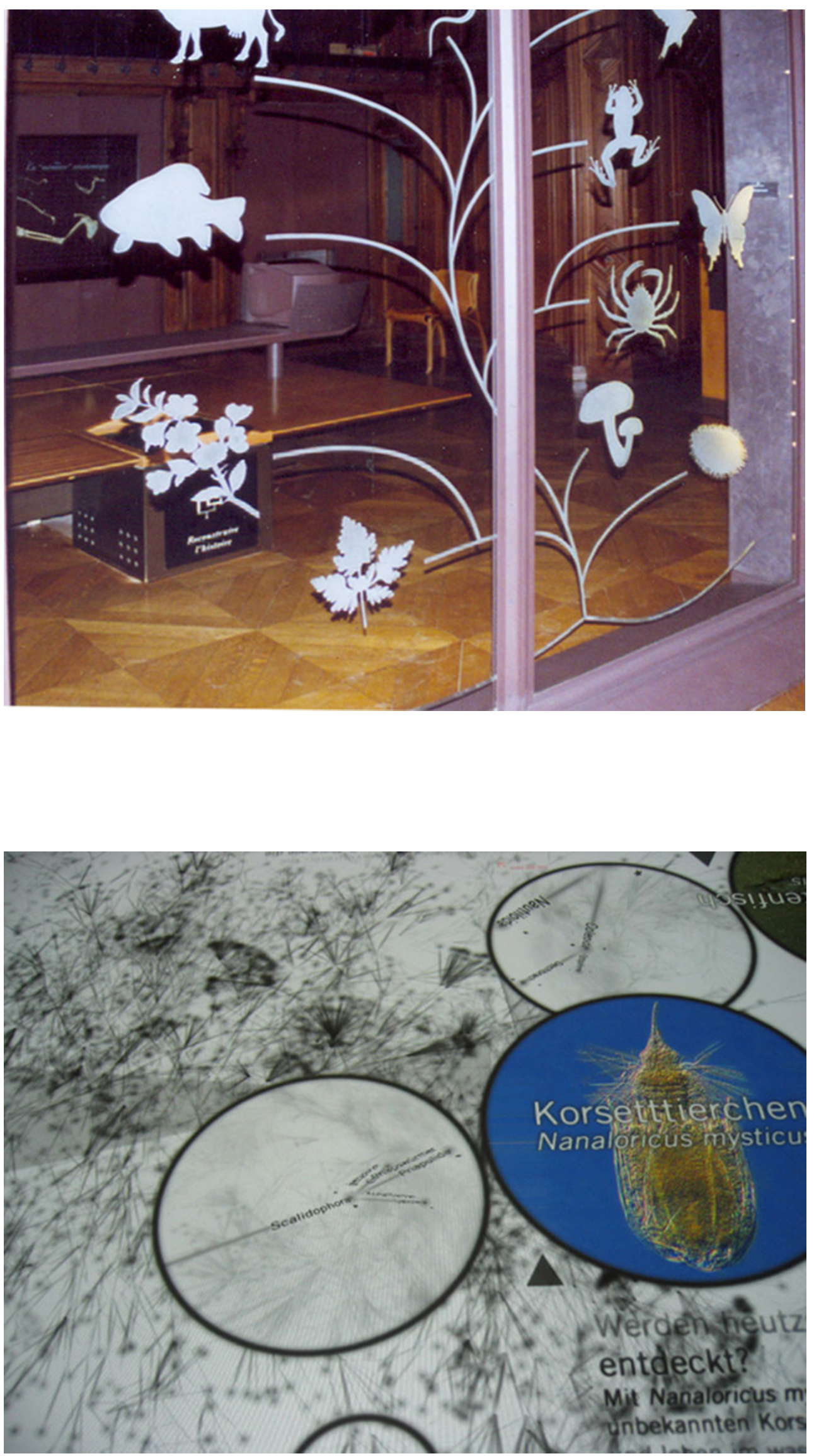


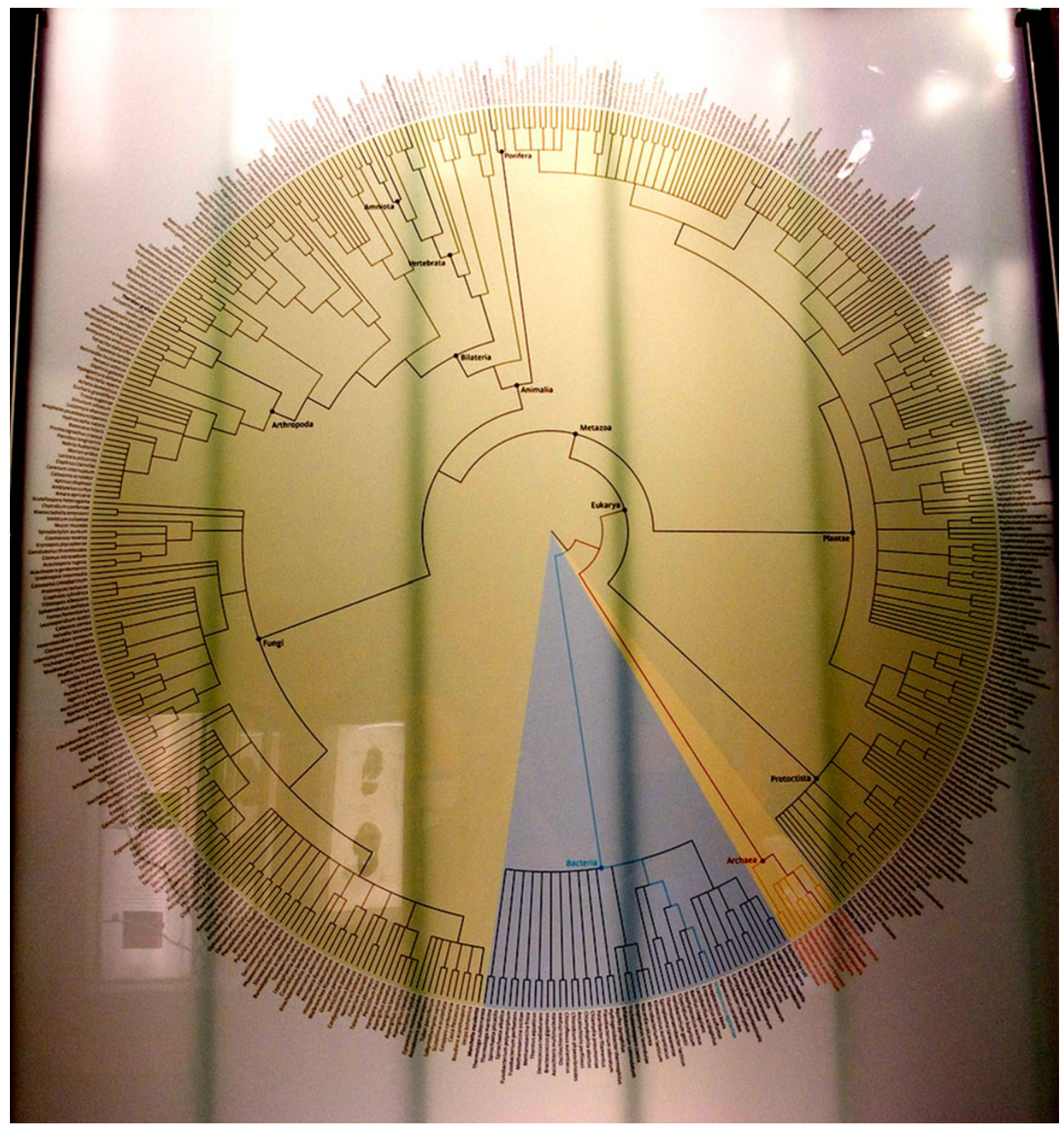

Fig. 17 Circular Tree at the Hall of Origins, American Museum of Natural History 


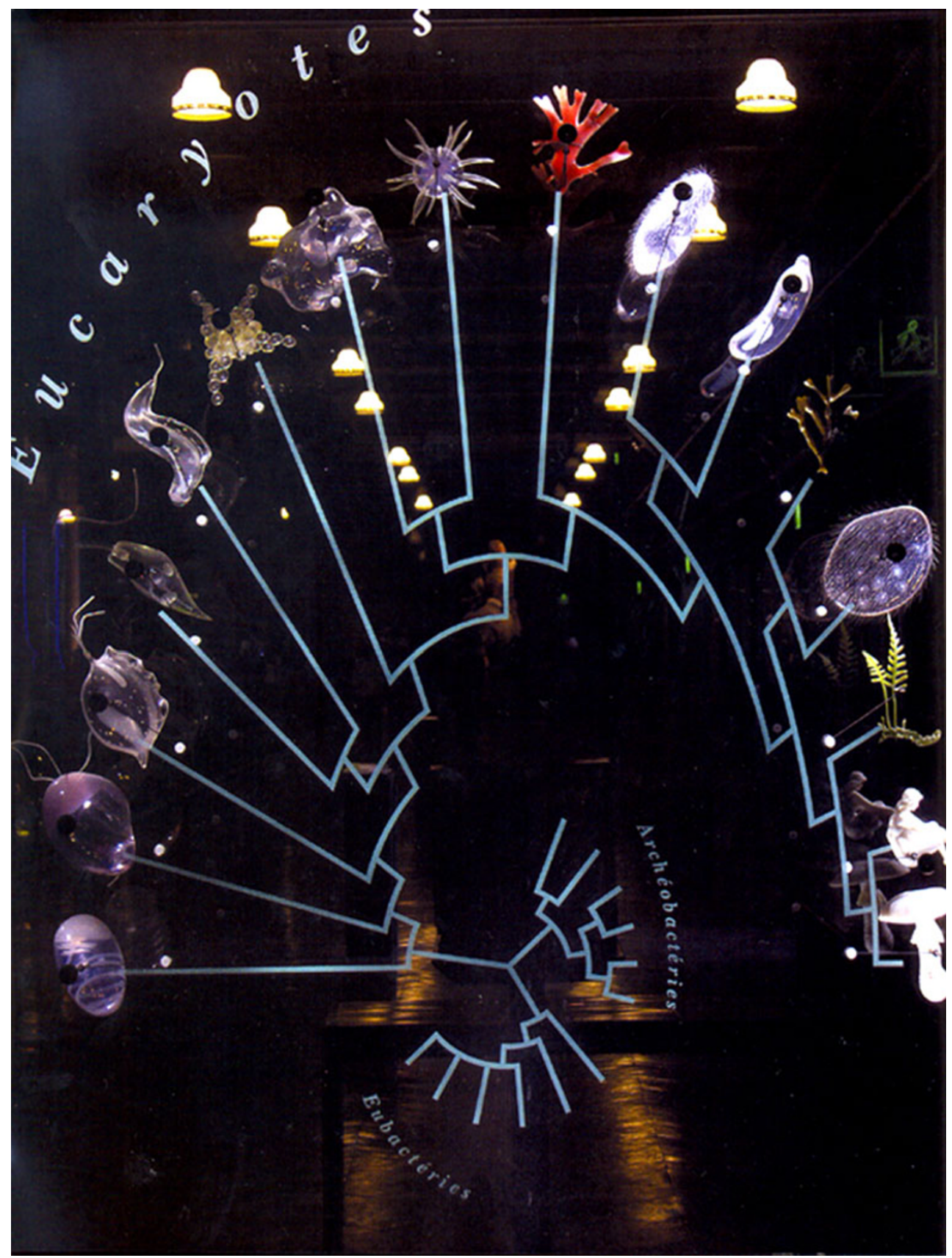

Fig. 18 Phylogeny of the three domains in the Great Gallery of Evolution, Paris

\section{References}

Baum D, Offner S. Phylogenies \& tree thinking. Am Biol Teach. 2008;70(4):222-9.

Baum D, DeWitt Smith S, Donovan SS. The tree thinking challenge. Science. 2005;310(5750):979-80.

Bishop BA, Anderson CW. Evolution by natural selection: a teaching module. Available at ERIC (Educational Resources Information Center). 1986;ED 272-383.

Catley KM, Novick LR. Seeing the wood for the trees: an analysis of evolutionary diagrams in biology textbooks. BioScience. 2008;58 (10):976-87.
Crisp M, Cook L. Do early branching lineages signify ancestral traits? Trends in ecology and evolution. 2005;20(3):122-8.

Diamond J, Scotchmoor J. Exhibiting evolution. Museums and Social Issues. 2006;Vol. 1, No. 1.

Dodick J. Phylogeny exhibits and understanding geological time. Harvard Museum of Natural History, Cambridge, MA: Paper presented at the Understanding the Tree of Life; 2009.

Evans EM. Tree-thinking: do pictorial representations of phylogenetic relationships help or hinder museum visitors' understanding of evolution? Harvard Museum of Natural History, Cambridge, MA: Paper presented at the Understanding the Tree of Life; 2009.

Gould SJ. Redrafting the Tree of Life. Proceedings of the American Philosophical Society. 1997; Vol. 141. No. 1 
Gregory R. Understanding evolutionary trees. Evolution, Education \& Outreach. 2008;1:121-37.

Matuk CF. Images of evolution. Journal of Biological Communication. 2007;33(3):E54-61.

Matuk CF. Animated cladograms: interpreting evolution from diagrams. Poster presented at the Fifth International Conference on the Theory and Application of Diagrams. Herrsching am Ammersee: Germany; $2008 \mathrm{a}$

Matuk CF. Animated cladograms: the perception and conception of evolution. Paper presented at the European Association for Learning on Research and Instruction (EARLI). Tilburg: The Netherlands; 2008b

Matuk CF. Animating trees of life: how animation influences the perception of evolution. Poster presented at the International Conference on Spatial Cognition. Freiburgh: Germany; 2008c

McDonald T. Communicating phylogeny: evolutionary tree diagrams in museums, Paper presented at the 2010 annual meeting of the National Association for Research in Science Teaching, Philadelphia: 2010
Meir E, Perry J, Herron JC, Kingsolver J. College students' misconceptions about evolutionary trees. Am Biol Teach. 2007a;69:71-6.

Meir E, Perry J, Herron J, Kingsolver J. College student's misconceptions about evolutionary trees. Am Biol Teach. 2007b;69:71-6.

O'Hara R. Telling the tree: narrative representation and the study of evolutionary history. Biol Philos. 1992;7(2):135-60.

Padian K. Trickle down evolution: an approach to getting major evolutionary adaptive changes into textbooks and curricula. From the symposium "Evolution vs. Creationism in the Classroom: Evolving students Attitudes presented at the annual meeting of the Society for Integrative and Comparative Biology, January 2-6, 2008 at San Antonio: Texas; 2008

Sandvik H. Anthropocentrism in cladograms. Biol Philos. 2007;24 (4):425-40.

Sandvik H. Tree thinking cannot taken for granted: challenges for teaching phylogenetics. Theory Biosci. 2008;127:45-51.

Tassy P. Trees before and after Darwin. J Zool Syst Evol Res. 2011; 49 (2), 89-101. 